\title{
O PROCESSO DE CONSTRUÇÃO DO DESIGN INSTRUCIONAL DO CURSO “INTRODUÇÃO À AUTOEDUCAÇÃO": ANÁLISE, DESIGN E DESENVOLVIMENTO
}

\author{
JOÃO PESSOA/PB MAIO/2018
}

\author{
Késsia Lopes Dutra - UFPB/DEMID - dutraissek@gmail.com \\ Signe Dayse Castro de Melo e Silva - UFPB/DEMID - signedayse@yahoo.com.br \\ Hercilio de Medeiros Sousa - UFPB/DEMID - contato@herciliomedeiros.com.br \\ William Bezerra da Silva - UFPB/DEMID - williamresista@gmail.com \\ Keyla Regina Oliveira Bonifácio - UFPB/DEMID - keylajob@gmail.com
}

Tipo: Relato de Experiência Inovadora (EI)

Categoria: Métodos e Tecnologias

Setor Educacional: EDUCAÇÃO SUPERIOR

\begin{abstract}
RESUMO
O presente texto relata a experiência de boa parte do Processo de Design Instrucional do curso Introdução à Autoeducação que foi desenvolvido no ambiente virtual de aprendizagem Moodle durante a disciplina Introdução ao Design Instrucional, ofertada no curso de graduação de Comunicação em Mídias Digitais, pela Universidade Federal da Paraíba. Foi-se analisado a percepção dos estudantes de Mídias Digitais em relação à Universidade e quais são as principais dificuldades que eles encontram quando estudam de forma autônoma. A partir da percepção dos estudantes e do conhecimento a cerca do significado de Educação e do Ensino Superior, o curso foi desenhado para mostrar novas perspectivas sobre Educação e oferecer aos estudantes uma introdução aos princípios e métodos da autoeducação, que, também, soluciona as dificuldades de aprendizagem autônoma que eles possuem. O curso foi desenvolvido no Moodle devido à acessibilidade do mesmo - a plataforma é gratuita - e por haver os recursos necessários que atenderam bem as propostas pedagógicas do curso. A previsão é que o mesmo seja implementado e avaliado no período de 2018.1 junto a disciplina de Metodologia do Trabalho Científico do curso de Comunicação em Mídias Digitais.
\end{abstract}

Palavras-chave: Design Instrucional, Ambientes Virtuais de Aprendizagem, Moodle, Autoeducação. 


\section{Introdução}

Este artigo é um relato de experiência a qual foi vivenciada durante a disciplina Introdução ao Design Instrucional, ofertada na grade curricular do curso de graduação de Comunicação em Mídias Digitais, pela Universidade Federal da Paraíba. A disciplina teve como produto o desenvolvimento de um curso utilizando o ambiente virtual de aprendizagem Moodle. Cada aluno ficou a vontade para desenvolver o curso de acordo com os seus conhecimentos e interesses pessoais.

Percebendo que o ambiente universitário no Brasil, devido a escolarização, abandonou a sua missão de transmitir um sistema de conhecimentos que permitia o indivíduo guiar a própria existência, e transformou-se em um meio de distribuir socialmente os indivíduos através de certificados e títulos - transformando a transmissão de conhecimentos em algo cada vez mais especializada e distante do conhecimento universal; e, percebendo também, como os universitários se frustram com a academia por reconhecerem nela uma extensão do ensino básico obrigatório, é que foi-se pensado em desenvolver um curso cujo o principal objetivo é resgatar a perspectiva de ensino superior perdida e oferecer para os estudantes que desejarem alcançá-la uma introdução aos princípios e métodos da autoeducação.

$\mathrm{Na}$ intenção de auxiliar primeiramente os estudantes do curso de Comunicação em Mídias Digitais, realizou-se uma pesquisa online através do Google Forms para verificar quantos deles estariam interessados em um curso online com tal proposta e, também, para identificar quais são as principais dificuldades dos estudantes em desenvolver o estudo autônomo. Aproximadamente, $87 \%$ dos alunos, que responderam o questionário, marcaram como interessante ou muito interessante a ideia de um curso que os visa auxiliar o desenvolvimento do estudo autônomo. E foi-se identificado como algumas das dificuldades de aprendizagem a falta de motivação, falta de atenção, fácil distração, gerenciamento de tempo, entre outros.

O curso, que logo ganhou o nome de Introdução à Autoeducação, foi desenvolvido com base nas teorias de Design Instrucional apresentadas por Filatro (2015), no que diz respeito ao Design Instrucional como Processo. As fases de Análise, de Design e de Desenvolvimento estão descritas no presente relato. As fases de Implementação e de Avaliação deverão ocorrer no período 2018.1 em conjunto com a disciplina de Metodologia do Trabalho Científico no curso de graduação de Comunicação em Mídias Digitais. 
Educação vem do latim ex ducere, que significa conduzir para fora. Através da educação, o indivíduo se liberta do egocentrismo cognitivo próprio da infância e se abre para o senso da unidade do real, buscando coesão entre memória e experiência, palavras e atos, percepções e pensamentos, etc. A capacidade de ação do ser humano começa restrita ao seu próprio corpo, mas tem a possibilidade de se estender para a humanidade inteira. A educação consiste em possibilitar a ampliação dos meios que o indivíduo tem de adquirir informações, de participação e de ação em círculos sociais cada vez maiores. Ligado a isso está a conquista da maturidade.

O homem maduro, no sentido aristotélico, é aquele que tornou sua alma dócil ao senso da unidade do real, aquele que faz da compreensão da realidade um hábito natural. Por ser capaz de compreendê-la, ele é capaz de guiar conscientemente a si mesmo e a comunidade na qual vive. Tal processo de submissão do pensamento à verdade, do desenvolvimento da personalidade intelectual, é que seria o objetivo da educação superior, a missão originária das universidades.

No entanto, a partir da expansão da ideia de um ensino universal e obrigatório, o sistema educacional ficou sob controle do Estado. A profissão docente transformou-se em um ramo da administração pública: um exame nacional foi instituído, o Estado passou a certificar os professores e a exigir o diploma para o exercício das profissões e para a entrada nas universidades. Assim, o sistema de ensino ocupou-se em produzir documentos ao invés de educação; preocupou-se em distribuir socialmente os indivíduos por meio de certificados e diplomas, transformando o ensino em um meio de promoção social onde o conhecimento transmitido é cada vez mais especializado e mecanizado, visando atender as demandas do mercado.

Esse sistema de ensino institucionalizado gerou na sociedade uma confusão entre serviço e valor. Criou-se a ideia de que o diploma é capaz de tornar o indivíduo alguém sábio e competente. No livro Sociedade Sem Escolas, Ivan Illich (1985) explica como funciona a ideia de escolarização na sociedade:

\footnotetext{
Muitos estudantes, especialmente os mais pobres, percebem intuitivamente o que a escola faz por eles. Ela os escolariza para confundir processo com substância. Alcançado isto, uma nova lógica entra em jogo: quanto mais longa a escolaridade, melhores os resultados; ou, então, a graduação leva ao sucesso. O aluno é, desse modo, "escolarizado" a confundir ensino com aprendizagem, obtenção de graus com educação, diploma com competência, fluência no falar com capacidade de dizer algo novo. Sua imaginação é "escolarizada" a aceitar serviço em vez de valor. (ILLICH, 1985, p. 16)
}

Então, mesmo nos ambientes universitários, onde o ensino não é mais obrigatório como no ensino básico, parte dos jovens se sentem pressionados a seguir em um curso que não Ihes agrada, apenas porque é um curso que tem prestígio social, porque o indivíduo 
conseguiu uma vaga para ele ou, ainda, porque é um desejo da família. Por outro lado, aqueles que possuem clareza dos seus objetivos na universidade, sentem-se insatisfeitos devido a imposição de determinadas disciplinas ligadas a uma grade curricular fechada que não permite a autonomia dos estudantes em reconhecer que tipo de conhecimento será relevante para suas perspectivas de futuro.

A educação só ocorre de forma efetiva através do ato voluntário do indivíduo em desejar e buscar o conhecimento. É uma conquista pessoal. Retirar este ato, que é um dever do indivíduo, para incutir a ideia de que educação é um direito, portanto é responsabilidade do governo, de instituições ou de pessoas fornecê-la, faz com que o indivíduo nunca tome a iniciativa "porque é obrigação recebê-la". Quando ofertada, é de uma forma limitada que não correspondem as necessidades do indivíduo. O máximo que pode ser oferecido para os indivíduos que desejam conhecimento são as oportunidades e os meios para que estes consigam educar-se a si mesmos.

Levando em consideração todo o conhecimento levantado acerca do que significa educação e ensino superior mais a experiência vivenciada no ambiente acadêmico nos últimos quatro anos, é que foi-se pensado em criar um curso utilizando o ambiente virtual de aprendizagem Moodle, onde os estudantes de Mídias Digitais possam ter uma outra visão do que significa educação, ensino superior e estudos, qual é a importância de buscar o conhecimento e, também, possam ter a disposição alguns princípios e métodos que possibilitam o ingresso em uma vida de estudos.

\section{Design Instrucional e Ambientes Virtuais de Aprendizagem}

O termo design tem relação com a concepção de um produto no que diz respeito a sua forma e funcionalidade, ou seja, com o trazer à superfície (através de modos sensoriais e cognitivos) as funções internas de um produto, mostrando que este possui propósitos claramente definidos. A instrução é uma atividade derivada do ensino e que objetiva buscar a aquisição de conhecimentos e crenças, utilizando-se da comunicação; também é capaz de auxiliar os alunos na construção de seus próprios conhecimentos, orientandoos através de feedbacks, por exemplo. Sendo assim, Design Instrucional, segundo Filatro (2004) é

uma ação intencional e sistemática de ensino, que envolve o planejamento, o desenvolvimento e a utilização de métodos, técnicas e atividades, materiais, eventos e produtos educacionais em situações didáticas específicas, a fim de facilitar a aprendizagem humana a partir de princípios de aprendizagem e instrução conhecidos.

Ainda segundo Filatro (2015), o conceito de Design Instrucional pode desmembrar-se em três grandes aspectos: como teoria (ou disciplina), como produto e como processo. 
Enquanto Teoria, o Design Instrucional está ancorado em três áreas essenciais: ciências humanas, com foco em psicologia comportamental, do desenvolvimento e da aprendizagem; ciências da informação e comunicação; e ciências da administração, por conta da gestão de projetos, abordagem sistêmica e engenharia de produção. Como Produto, está relacionado ao fato de expressar os objetivos, os métodos e as estratégias utilizadas para alcançar uma solução educacional; esta solução pode vir como forma de um podcast, livro impresso ou digital, infográfico, jogo, entre outros. O Design Instrucional como Processo se encontra na citação feita anteriormente, com a diferenciação em relação a sua abrangência: em nível macro, ocupa-se em definir diretrizes comuns as ações de aprendizagem de uma instituição, por exemplo; em nível meso, dedica-se a estruturar cursos ou disciplinas; e em nível micro, o design das unidades de estudo.

Para os níveis macro e meso é comum que se adote modelos de Design Instrucional para a produção de conteúdos educacionais: o Design Instrucional Fixo (DI Fixo) tem como principais características conteúdos educacionais inéditos, ricos em mídia, produzidos antecipadamente à situação didática, interação individual com conteúdos, realização de atividades objetivas a partir de orientações gerais para o participante, a autoavaliação (por gabaritos de respostas ou feedbacks automáticos); o Design Instrucional Aberto (DI Aberto) possui conteúdos próprios ou de terceiros, disponíveis em diferentes formatos, linguagens e mídia, organizados por meio de links de acesso ou para download individual, realização de tarefas abertas de interação com outras pessoas (discutir em fóruns, atividades colaborativas e etc.); o Design Instrucional Contextualizado (DIC) também trabalha com conteúdos próprios ou de terceiros, em diferentes formatos, linguagens e mídias, são compatíveis ou não com padrões interoperáveis, costumam estar disponíveis para acesso em repositórios específicos a partir de buscas com base em metadados, a realização de atividades pode ser aberta ou fechada, coletiva ou individual, onde o acompanhamento é personalizado, préprogramado e disparado automaticamente.

No entanto, independentemente do modelo escolhido, o processo de Design Instrucional é composto de cinco fases: Análise, onde identifica-se as necessidades de aprendizagem, define-se os objetivos educacionais, caracteriza o público-alvo, etc; Design, onde todo o planejamento educacional é registrado em um roteiro de atividades pedagógicas; Desenvolvimento, é a parte própria da produção de conteúdos; Implementação, é quando os produtos produzidos são aplicados e colocados em teste; Avaliação, onde é mensurado a efetividade da proposta de solução educacional e a aprendizagem dos alunos. 
Segundo Almeida (2003, p.331), os Ambientes Virtuais de Aprendizagem (AVAs):

[...] são sistemas computacionais disponíveis na internet, destinados ao suporte de atividades mediadas pelas tecnologias de informação e comunicação. Permitem integrar múltiplas mídias, linguagens e recursos, apresentar informações de maneira organizada, desenvolver interações entre pessoas e objetos de conhecimento, elaborar e socializar produções tendo em vista atingir determinados objetivos. (apud KAY, 2014, p.84)

Dentre os diferentes tipos de Ambientes Virtuais de Aprendizagem disponíveis, o Moodle foi escolhido para se trabalhar na disciplina de Introdução ao Design Instrucional por ser gratuito, possuir bons recursos e atividades que os professores podem utilizar, ter um sistema de código aberto que permite a personalização do ambiente, acrescentando funcionalidades através de plug-ins de acordo com os objetivos de aprendizagem, e por ser o mais popular.

\section{Sobre o curso Introdução à Autoeducação}

O termo autoeducação traz um paradoxo em si: toda educação é uma autoeducação porque o sujeito ativo do processo educacional é o aluno e não o professor ou a instituição, porém não é possível que alguém se autoeduque plenamente sem algum auxílio externo, ou seja, sem algum modelo, alguma finalidade, algum material que inspire a busca pelo conhecimento e seja de onde o indivíduo irá retirar as suas referências. O nome do curso - Introdução à Autoeducação - propõe que ele mesmo seja um primeiro contato, uma primeira referência dos princípios e métodos que possibilitarão os estudantes de Mídias Digitais a desenvolverem uma autonomia sobre os próprios estudos.

O curso tem como objetivo geral sensibilizar os estudantes do curso de graduação de Comunicação em Mídias Digitais que o estudo vai além de uma sala de aula, de conteúdos programados, que pode ter um significado para além da obtenção de notas, diplomas, emprego, aprovação etc., a fim de promover os meios necessários para o desenvolvimento intelectual daqueles que desejarem. Entre os objetivos específicos estão: proporcionar sentido aos estudos, criação de rotina de estudos, viabilizar o conhecimento dos diferentes níveis de leitura favorecendo a compreensão de qualquer leitura e desenvolver os métodos de pesquisa. Como diferencial, os conceitos abordados no curso serão de uma perspectiva clássica, que foge do senso-comum, trazendo um novo olhar sobre o assunto e que agregará valor até mesmo aos estudantes que já possuem certa independência nos estudos.

Inicialmente, o curso será ofertado apenas para os estudantes de Mídias Digitais, pois sua implementação está prevista para o período de 2018.1 em conjunto com a disciplina 
de Metodologia do Trabalho Científico. Então, como pré-requisito, é necessário que o aluno interessado em fazer o curso seja ativo no curso de Comunicação em Mídias Digitais, tenha acesso regular à internet e deseje desenvolver-se intelectualmente. $\mathrm{Na}$ pesquisa prévia realizada com os estudantes para saber o interesse dos mesmos em um curso com tal proposta e quais são as principais dificuldades que eles encontram no momento de estudar por conta própria, foi identificado dificuldades de concentração, de atenção, de motivação, de gerenciamento de tempo, de excesso de informações, pouco ou nenhum incentivo para se desenvolverem intelectualmente, ver a universidade apenas como um meio de adquirir qualificação profissional.

A estrutura do curso Introdução à Autoeducação conta com quatro módulos que abordam, na respectiva ordem: a importância do estudo autônomo; o estado de ordenação para iniciar os estudos, desde a organização da vida, do ambiente, até o material que será utilizado; como criar o hábito de estudo; e como exercitar a mente durante a leitura. Dentre os recursos do Moodle foram utilizados, principalmente, Upload de Arquivos - para compartilhar capítulos de livros e artigos - e URL de Videos. Também foram utilizados os recursos de: Fórum, para debates do conteúdo exposto; Envio de Tarefas, para que os alunos possam ser avaliados, também, de forma individual; Questionários, que permitem o feedback automático do exercício; e Pasta, para montar uma biblioteca com leituras complementares de referência.

As figuras 1, 2, 3 e 4, a seguir, permitem a visualização de como o curso está estruturado na plataforma.

Figura 1: Estruturação do curso no Moodle

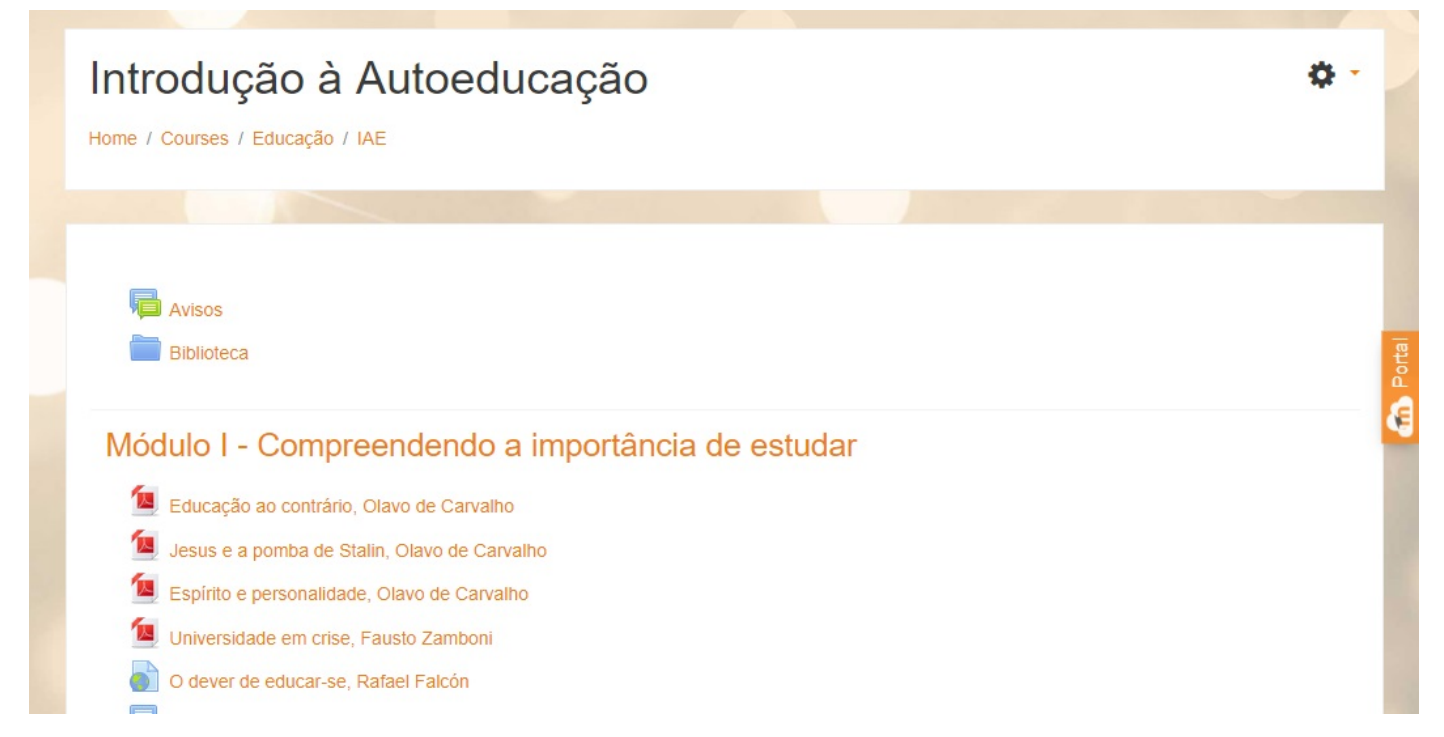

Fonte: Próprio Autor (2018) 
Figura 2: Material disponibilizado no Moodle

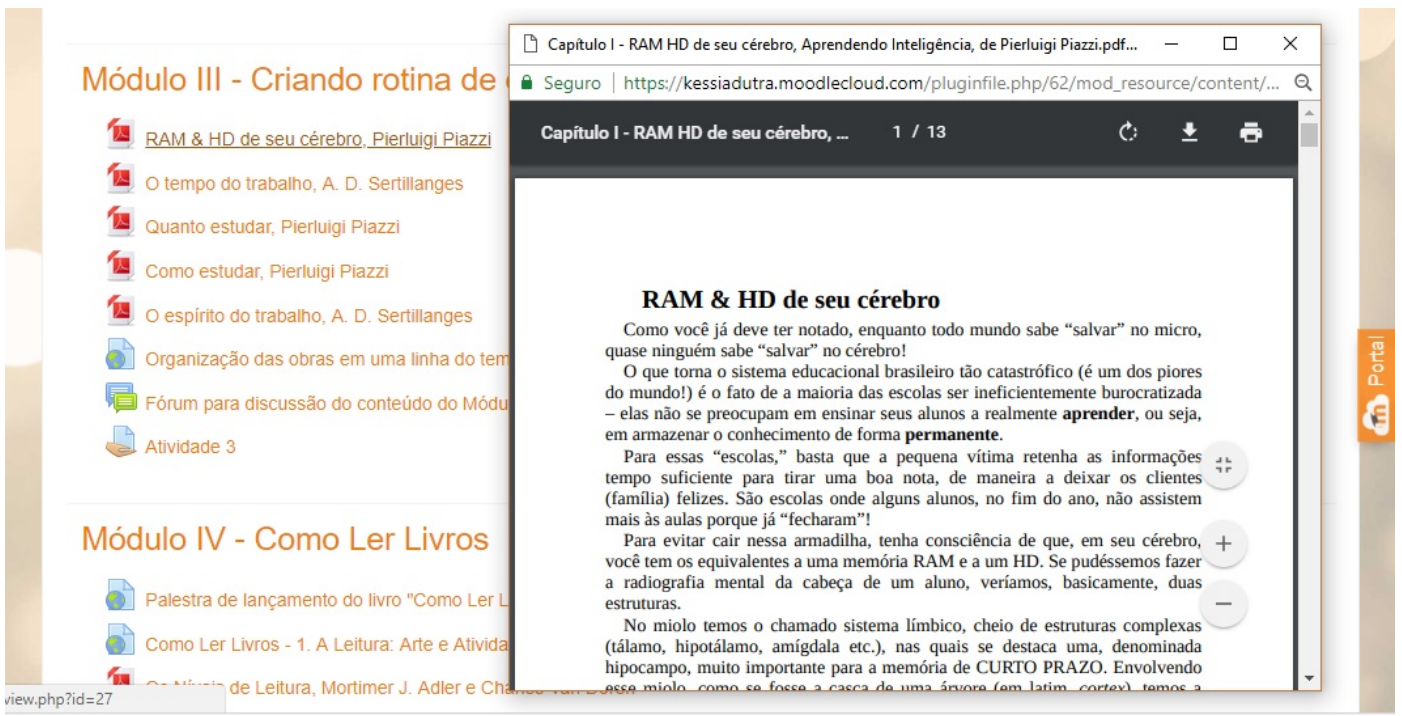

Fonte: Próprio Autor (2018)

Figura 3: Vídeo disponibilizado no Moodle

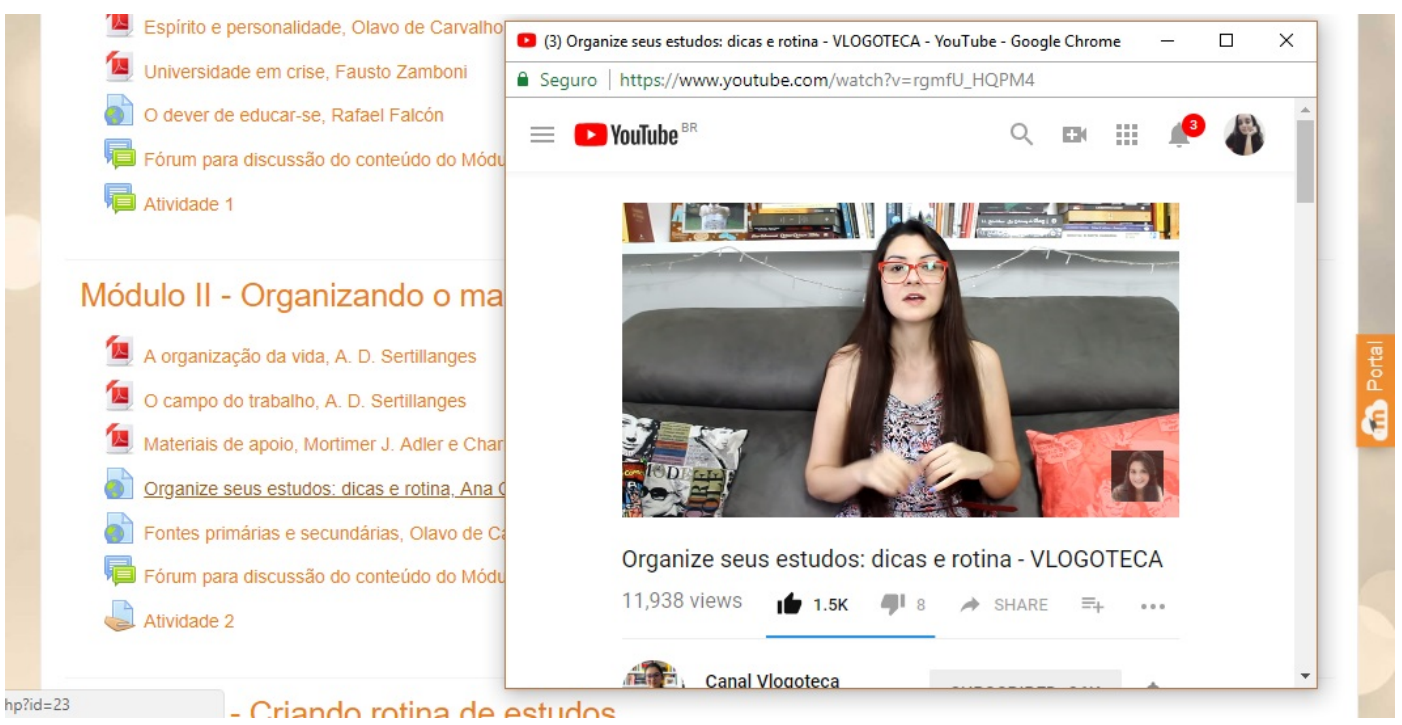

Fonte: Próprio Autor (2018) 
Figura 4: Atividade disponibilizada no Moodle

\section{Introdução à Autoeducação \\ Home / Courses / Educaçăo / IAE / Módulo III - Criando rotina de estudos / Atividade 3}

\section{Atividade 3}

Iniciar a leitura do livro escolhido na atividade anterior e fazer anotações dos principais autores/obras mencionados. Fazer uma linha do tempo com o nome do autor, obra, data de publicação, data de reconhecimento da obra, breves comentários para contextualizar a época etc. Enviar tarefa, segundo o

template, nos formatos aceitáveis (.gdoc, .odt, .docx, .rtf, .doc)

W. Seu nome - Atividade 2 (modelo).docx

Grading summary

Participants

Submitted

Needs grading

Fonte: Próprio Autor (2018)

Espera-se que este curso possa trazer uma nova reflexão sobre o papel das universidades brasileiras atualmente, que os estudantes de Mídias Digitais possam amadurecer e buscar o conhecimento pelo resto de suas vidas e que em breve o curso esteja disponível para um público maior.

\section{Referências Bibliográficas}

CARVALHO, Olavo de. Jesus e a pomba de Stalin, 20 de outubro de 2001. Disponível em: http://www.olavodecarvalho.org/jesus-e-a-pomba-de-stalin/. Acesso em: 17 de maio de 2018.

Espírito e personalidade, 31 de janeiro de 2013. Disponível em: http://www.olavodecarvalho.org/espirito-e-personalidade/. Acesso em: 17 de maio de 2018.

. Educação ao contrário, 27 de janeiro de 2009. Disponível em: http://www.olavodecarvalho.org/educacao-ao-contrario/. Acesso em: 17 de maio de 2018.

FILATRO, Andrea. Design instrucional contextualizado: educação e tecnologia. São Paulo: Editora SENAC São Paulo, 2004. 
ILLICH, Ilich. Sociedade sem escolas. Petrópolis: Vozes, 1985.

JOSEPH, Miriam. O Trivium: as artes liberais da lógica, gramática e retórica: entendendo a natureza e a função da linguagem. São Paulo: É Realizações, 2008.

KAY, Viviane Naomi. Ferramentas Web 2.0 para Atividades em Educação a Distância, utilizadas em conjunto com o Ambiente Virtual de Aprendizagem Moodle. Rev. EaD \& Tecnologias Digitais na Educação, Dourados, v.2, n.3, p.81-93, Jan/Nov 2014.

ZAMBONI, Fausto. Contra a escola - Ensaio sobre literatura, ensino e Educação Liberal. São Paulo: VIDE Editorial, 2016. 